\title{
The Influence of Transnational Practice on Foreign Language Learning
}

\author{
Zhao Hui ${ }^{1}$ \\ ${ }^{1}$ School of Foreign Language \& Trade, Nanhua College of Industry and Commerce, \\ Guangzhou, Guangdong, China
}

\begin{abstract}
This paper takes business Japanese major of Nanhua College of Industry and Commerce as an example to explore the influence of transnational practice on foreign language learning. Sending students to practice in Japan is a reform of Japanese teaching in our school. The students who pass the interview will practice in Japan for three months. It can not only combine theoretic knowledge and practice, but also widen the scopes of the students and improve their work ability and language skills. Meanwhile, the problems exposed in the internship reflect the deficiency of foreign language teaching that need to be improved.
\end{abstract}

Keywords: Transnational practice; practical teaching; Japanese teaching; vocational colleges

\section{INTRODUCTION}

Japan's aging society is growing and the young and middle-aged labor in Japan decrease year by year. With the increasing costs of manufacturing industry in China and the improvement of science and technology, the number of Japanese enterprises in China collapses. Many factors lead to the growing difficulty of employment of business Japanese major. At the same time, more and more students choose to go abroad to study. Comparing with usual, the scale of domestic enrollment has a huge shrink. In this context, it becomes a huge problem that how to make business Japanese major be characteristic. Practice teaching project in Japan provides students with internship opportunities. Undoubtedly, it strengthens their language ability also increases the experience for job-apply by combining Japanese what they learned in class with the practice, which is definitely a good way to improve their jobs.

In order to further improve the language application ability of business Japanese majors, and strengthen students' social practice knowledge and skills training, the college and school leaderships decide to send business Japanese specialty students to go to Japan to practice and carry out practice teaching cooperative project in terms of professional prospects and the teaching quality.

\section{Project development status and the evaluation to students}

Taking the author's school as an example, the number of practice has increased year by year since the first batch of 2 students to practice in January 2013. As of March 2015, our school sent a total of 6 batches of 60 students. The practice unit will evaluate the students' internship performance.

In the performance evaluation of the students in the internship period, a lot of evaluation is positive and sure. Students' language level, communication skills and ability to work are to be recognized. Especially for the students who perform well in all aspects, they will be awarded a certificate. There are two students in recognition of their outstanding performance as of a recent internship (March 2015).

There is some evaluation from the internship unit in each student's practice identification table. Internship unit can understand students' error or inadequate in the process from never adaption to adaption. Most of the students who have an open mind to study and work hard receive full recognition. In particular, the students' efforts and progress are seen in the eyes of the internship unit and to be sure, and the unit gives great expectations of the students' future development. However, the enterprises for internships gave some harsh comments on students with less impressive language ability and less hard-working attitudes, especially with no motivation. In fact, during the beginning of the project of the practice, the supervisors of our college and the Japan's had a slack regulation on this matter, which triggered a girl student receiving a negative comment. After such an evaluation appears, firstly the school is in strict control. For the students who are lack of conduct and ability, the school will not recommend them to the interview, so as to prevent the recurrence of such things. At the same time, it also gives certain pressure to the students in the school who want to go to Japan, and the students must be aware of the need to do well in all aspects in order to achieve the dream of internship.

\section{Gains of internship students}

During the three months of internship, the students experience the Japanese life, learn Japanese social culture, 
and have a great harvest in thinking, language and other aspects.

(1) Experience the living environment of the Japanese. Although many teachers have talked about the general situation of the Japanese people and Japanese environment in the normal class, but students are still moved by Japanese beautiful natural scenery, good humanistic quality and strict social order when they truly arrive in Japan. The students are shocked: originally the Japanese can really do this well. All practice students are the first time to experience the difference between countries. Through the project cooperation, the classroom content and practical knowledge are combined, so that learning is more vivid and memorable.

(2) Personally experience Japanese social culture. Internship students truly experience the Japanese social culture: a lot of rules and regulations, high attention to etiquette, attention on relationship and working attitude at work, and more use of greetings and honorific than expected. Greetings are very important, and especially in the face of the boss and the guest, honorific greetings must be used. In Japan the internship students also need to pay attention to exchange greetings with colleagues. At the beginning of the internship in Japan, many students are not used to keeping greetings, and some students do not think that it is necessary to have some greetings that seem no practical significance every day, and do not take the initiative to speak. As a result, the evaluation was "does not love to communicate".

(3) Japanese people have a strong sense of time and high standard about the work. The Japanese are very strict when they are at work, and they are very patient with the novice to guide, but will play with everyone when not working. You must be serious with work at work time. For the requirements from the higher level, the staffs do not generally complete, but try their best to do the same. For example, the location of each cup, the procedures of each floor cleaning and so on. What they do is very close with the requirements. This is a manifestation of the Japanese professional spirit. Some students said: in the three month internship, I have learned more than the use of a language, but a national spirit, a culture and a kind of self-cultivation.

(4) The students' ideological consciousness has changed, and they are more mature and responsible. At the beginning of the cooperative project, there are some students thinking that practice is only in the name of practice, and then they held a kind of attitude of travelling to visit Japan. As a result, the students can't adapt to the real work content, and even have a feeling of being cheated. The author thinks that it is actually led by students' no right consciousness to practice. Therefore, after the students pass the interview, the teachers have repeatedly stressed that practice is to learn and work, and it combines Japanese and work together to learn. The awareness of the students gradually changes, and the consciousness is more and more practical. Thus they have positive attitude in practice. Some students said that they thought a lot and knew the objective was to learn on the plane to Japan. They told themselves that no matter what difficulties they would encounter, they must be strong; no matter how hard the work was, they must also insist; even if they must wash the toilet every day, they would do the best. Some students summarized the internship and said: the three month was the most valuable experience for them in the life and exercised their abilities, and they felt that no matter how difficult it was, they could stick to the end.

(5) Language ability has been improved. One of the purposes of practice for many students who go to Japan is to improve Japanese. The students who passed the interview are relatively strong and more self-confident in listening and speaking ability. However, when they first arrived in Japan, all reflect that the Japanese speak too fast; they do not know many of the words, and the use of foreign language is very frequent. So it is difficult to communicate with the Japanese normally at the beginning. Sometimes they cannot understand the meaning, and most of the time, they can understand each other but cannot express their own ideas. Fortunately, the Japanese are very enthusiastic and patient. They will do the demonstration and give patient explanation when the students cannot understand the meaning. So students do not have to worry too much that their Japanese is bad and will be criticized.

In practice, students are in the face of the Japanese only, whether with colleagues or guests, and can only use the Japanese. In such an environment, the students have to learn Japanese. Generally speaking, communication difficulties will last for two weeks to a month. After that, there is no problem in Japanese in the daily exchange and the content of work. Of course, there are very individual students reflecting: in these three months, almost every day is the same, and they do things and talk is very little; even in the work, they only use a few words after all; if you don't continue to learn Japanese, it is difficult to improve the Japanese language in practice in Japan. Therefore, we advocate that the students should take advantage of the environment in Japan and initiatively find topics to communicate with others to improve Japanese. Some students said that because the Japanese often used foreign language, it was very important to learn English. Thus, you must continue to learn English when learning Japanese.

\section{Enlightenment of practical teaching}

Internship is a prelude to the students when they are really into the job. After the students work, they will again be in face with all the gains and losses in the practice. The problem reflecting in internship stage can also be understood as the problem a student will encounter when enters the work. According to a survey about Japanese students' internship experience and working condition, the author thinks that it is necessary to do a lot of reform about traditional Japanese teaching objectives and teaching 
methods in order to develop higher vocational talents of Japanese in line with the demand of the society and work units. Specifically, as the following points:

(1) Changing the traditional personnel training objectives. Like the undergraduate school, a lot of higher vocational colleges also set the five indexes, "listening, speaking, reading, writing, translation", as the training objectives of foreign language talents. The author thinks that it is very difficult to develop the college students into the Japanese talent in the five aspects in a short span of three or two years. As you can see, many students spend a lot of time and energy reading, writing, and translating. However, the harvest and pay is not directly proportional. Many students can understand, read and translate Japanese, but the ability of listening, speaking and interpretation is very low. A lot of students aren't strict with themselves, and they think it's as long as to read and write well, and do not pay attention to the cultivation of listening and speaking ability. However, the foreign language talent who can only read and write and can't listen and speak can't meet the needs of the community. The society needs talents who are good at listening, speaking and translating. The author believes that the training target of higher vocational Japanese major should focus on these three points of listening, speaking and translating, cultivating the abilities of listening, speaking and translating. Correspondingly, the teaching mode should be changed.

(2) Changing the traditional Japanese teaching mode. Most Japanese language learners start to learn Japanese after they enter the university. All the words and grammar need to be learnt, so the basic Japanese language teaching set up a large proportion in the Japanese course. The author believes that the objective of basic Japanese language teaching is not to remember words and grammar through learning words and grammar, but by learning words and grammar to cultivate students' ability to listen, speak and translate. Therefore, the focus of teaching is not that the teacher explains each word and grammar and students recite these explanations, but that students utilize learned vocabulary and grammar to train their listening, speaking and translation abilities. After clearly explain the usage of important word and sentence meaning, the teachers can do bilingual translation by using the learn content, or guide the students to retell the text content, or design scene to do scene training. As a result, the proportion of the students' listening and speaking increase; the opportunities of listening, speaking and translation increase; relatively speaking, the ability of listening, speaking and translation has been improved.

(3) Strengthen foreign language and English learning. The words of Japanese include Chinese, Japanese language and foreign language, and most of the words have three kinds of statements, Chinese, Japanese language and foreign language at the same time. Much of the foreign language is a transliteration of English words. You'd better study the transformation law of the pronunciation of words of foreign language and English. So, even if you have never learnt foreign language, it will be easy to come up with it if your English is good and you can associate English words from the pronunciation of the words. In turn, if you master many English words, you can also communicate with Japanese by converting into Katakana words through transliteration, and your word quantity correspondingly increases a lot.

(4) Simulate an environment in which communicate with the Japanese. Specifically, when you meet the classmates or the teachers, you should exchange greetings, and speak Japanese when you enter the classroom. Teachers teach in Japanese language in class, and encourage students to communicate in Japanese. At the beginning of learning Japanese, in order to enable the students to hear clearly, teachers' speed can be slow, but when it reaches a certain stage, teachers should try to use natural speed to teach. Especially the foreign teachers in class, if their speed is too slow in order to make students understand, students will adapt to this speed and be not used in real environment of Japanese speech. Set up the cultural class about Japanese etiquette, and learn Japanese common etiquette. Set up more projects to train, strengthening the training of honorific performance, and improving the level of honorific expression. Use multimedia to play video, pictures, etc. in order to more publicize today's Japan, so that students have a more intuitive understanding of Japan's geographical environment, social culture, etc.

(5) Develop right labor concept and work attitude, and finish job with high quality. From the students' practice environment and the evaluation of students from the practice units, it is very important and has practical significance that the young people establish right labor concept and work attitude. College students' pressure of social work will continue to increase in the future. Those who are picky about work selection and have unrealistic expectations will not be favored labor. Similarly, the personnel who don't pay attention to detail in work, and don't complete the work requirements with high quality will not meet the requirements of social development. Therefore, it is one part for foreign language teaching experts of higher vocational colleges in the process of teaching that educate students to set correct labor concept, cultivate right work attitude, and work with high quality.

\section{Conclusion}

Practice teaching of Japanese is an innovative method in Japanese studying. It can not only combine theoretic knowledge and practice, but also widen the scopes of the students, and improve work ability and language skills. Meanwhile, the unfitness and problems exposed in the internship reflect the deficiency of foreign language teaching in higher vocational colleges. Students gain much knowledge from the practice. It is a meaningful way to improve the quality of teaching. 


\section{References}

[1] L Huo, G Feng. Reflections on cultural introduction in Japanese Teaching. Shanxi Education (Higher Education Edition), 2008.03:23-24

[2] $\mathrm{H}$ Yang. The practice and evaluation of Japanese professional overseas practice -- Taking Ningbo University of Technology as an example. Journal of Ningbo University of Technology, 2015.01:118-122

[3] L Guo. Research on the development and utilization of the practical teaching resources of Japanese major in Colleges and Universities. Journal of Taiyuan City Vocational College, 2015.03:157-159

[4] J Wang, P Wu. Talking about the role and impact of training in Japan. Journal of Shandong Institute of Commerce and Technology, 2013.02:55-57 